\title{
Proteo y la Desapropiación del Tiempo en SIMONE WEIL
}

\author{
Juan Manuel Ruiz Jiménez ${ }^{l}$
}

Resumen: En este trabajo estudiamos la génesis de la concepción de la percepción de Simone Weil. Apoyándonos en algunos textos clave de juventud de la autora, hacemos el seguimiento al manejo que le da la filósofa a la figura mitológica de Proteo y a las nociones de tiempo y espacio. Así, nuestra intención es evidenciar la aparición de los principales fundamentos teóricos que estructurarán la fenomenología weiliana de los años de madurez. ${ }^{2}$ En este sentido, intentamos demostrar en particular que si bien el proceso perceptivo weiliano de los años de juventud está determinantemente influenciado por la fenomenología kantiana, aparece ya un aporte original en lo que atańe a la relación de la conciencia del sujeto y los datos espaciotemporales que se le revelan al aprehender el objeto.

Palabras Clave: Proteo. Tiempo. Espacio. Percepción. Deseo.

\section{INTRODUCCIÓN}

La cuestión del tiempo es sin lugar a dudas uno de los temas más importantes en la obra de Simone $\mathrm{Weil}^{3}$, omnipresente en todos sus objetos de reflexión y periodos de su vida ${ }^{4}$. Lo que lo explica es que para esta filósofa se

${ }^{1}$ Actualmente profesor de filosofía y estudios literarios en el Departamento de Humanidades y Filosofía de la Universidad del Norte, Barranquilla, Colombia. E-mail: juanmr@uninorte.edu.co

2 Entre 1933 y 1938 Simone Weil escribe en el Cahier I dos pasajes que revelan la influencia cartesiana y Kantiana en su concepción fenomenológica en relación con el trabajo que la razón debe ejercer sobre nuestra imaginación a la hora de juzgar los datos de la percepción sensible, sin lo cual viviríamos engañados en medio de ilusiones ópticas: "La percepción es impotente a partir de cierta complicación si el razonamiento no viene a nuestro socorro" (WEIL, 1994, p. 74) y en otro pasaje: "Lectura. Leo un cubo en una caja. Si sé que actúo hacia esa caja como respecto a un cubo, lo lograré." (WEIL, 1994, p. 184)

3 Tal y como lo observó tempranamente Gilbert Kahn (1985, p. 221) al calificarlo como "cuestión central" ya anunciada en la reflexión weiliana de 1926 que concierne la relación entre eternidad y tiempo en la música.

${ }^{4}$ En efecto, en la última década, a medida que se ha incrementado la atención sobre la obra weiliana, se ha abierto el abanico de los estudios sobre esta, los cuales orbitaban casi que exclusivamente alrededor de la noción de trabajo, merced al trabajo de Chenavier (2001). En este sentido, Gabellieri tiene razón al afirmar que "[...] la reciente obra de R. Chenavier, Simone Weil. Une philosophie du travail, constituye la última, a la fecha, de esos intentos de síntesis, intento cuya originalidad, respecto a todas las lecturas anteriores, es la de proponer ver en el concepto de trabajo el núcleo central del pensamiento weiliano. [...] ¿Pero hay que (y puedo uno concluir) que el trabajo es «el» centro del pensamiento weiliano ?" (GABELLIERI, 2003, p. 14).

http://dx.doi.org/10.1590/S0101-31732017000300007 
trata de una instancia que permite comprender el conjunto de las dimensiones de la realidad humana. En este sentido, lo que me propongo en este artículo es hacer un bosquejo general, un análisis y una interpretación de los principales hitos, bases e influencias filosóficas a los que Weil recurrió para estructurar su concepción del tiempo. Es por esta razón que el presente estudio se centrará en algunos textos representativos de su primera época, que recogen ya los parámetros básicos de su concepción de lo temporal, esto es entre los años 1925 y $1931^{5}$, que corresponden a sus ańos de juventud. En su prima época, la cuestión del tiempo se instala ya como un interrogante fundamental en su pensamiento, y desde sus primeros textos la filósofa comienza a construir una concepción original del tiempo. Ahora bien, esta última, si bien es el resultado de una reflexión personal, estuvo fuertemente influenciada por el pensamiento de varios filósofos. En este orden de ideas, intentaré establecer quiénes son ellos y en qué medida se operó esta influencia. Estudiaré igualmente la forma como ella adaptó y modificó este bagaje conceptual con el fin de incorporarlo a su propio pensamiento. Dentro del tema del tiempo, en particular me centraré en el problema de la inestabilidad de la percepción humana. Para hacer este bosquejo, primeramente abordaré la concepción weiliana del espacio a través de la figura mitológica de Proteo, que tanto inspiró a Weil en su juventud; y en un segundo punto abordaré la concepción weiliana del tiempo.

\section{Proteo}

Juzgo prudente poner previamente en claro algunos puntos que conciernen al pensamiento weiliano del espacio, para volver con más luces a la cuestión del tiempo. En primer lugar, hay que aclarar que por lo menos hasta 1937, Weil considera completamente válida la formulación kantiana del tiempo y el espacio como formas de nuestra intuición, expuesta en la Crítica de la Razón Pura ${ }^{6}$. Cito un pasaje de Weil que explicita la influencia todavía dominante del pensamiento de Kant en ella:

\footnotetext{
${ }^{5}$ En este sentido, Miklos observa acertadamente que si bien los trabajos weilianos de juventud "[...] se caracterisan por un estilo altamente complicado y denso, por un razonamiento apretado y por un tono majestuoso y definitivo [...] son una fuente muy importante de información sobre la génesis de su pensamiento." (MIKLOS, 1997 p. 14).

${ }^{6}$ Fiel a la concepción kantiana expuesta en la Crítica de la Razón pura, Simone Weil buscaba renovar la filosofía mediante una metafísica que se limitara al marco de la experiencia posible. Por esta razón, estamos de acuerdo con Philippe Riviale cuando afirma que es por "[...] la metafísica por lo que en sobre manera el pensamiento de Simone Weil cobra todo su sentido.” (RIVIALE, 2004, p. 7).
} 
El tiempo parece ser la forma misma de la existencia. [...] Es acertado decir que se le puede llamar al tiempo una forma de la existencia; porque la existencia es por excelencia lo que es informe. Kant veía en el tiempo, como en el espacio, una forma a priori de la sensibilidad; y hay que afirmar primero que todo que este análisis de Kant es verdadero como el resto de su obra. (WEIL, 1988, p. 74).

En segundo lugar, es determinante tener en claro quién es Proteo, que

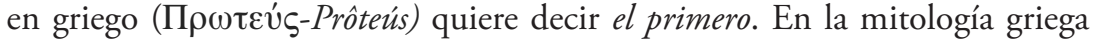
se trata de una divinidad marina, un viejo del mar, hijo de Poseidón, capaz de metamorfosearse a voluntad y dotado del don de profecía. Como es de imaginar, todos querían hacerle decir sus predicciones, pero él sólo las revelaba a quien lograra capturarlo. En la Odisea se evoca a Menelao desesperado porque, de regreso de Troya, no logra retornar a Grecia, pues no sabe cómo salir de la isla de Pharos, en donde los dioses lo habían bloqueado por no haberles rendido sacrificios luego de la guerra. Menelao captura pues a Proteo, tendiéndole una trampa (se disfraza de foca, y se esconde entre las focas del dios) para hacerle preguntas que le permitan saber qué debe hacer para volver a casa. Lo captura, pero la divinidad, al querer escapársele, intenta cambiar varias veces de apariencia, como último recurso para camuflarse y huir. Basada en este personaje, Weil compara el proceso de definición de la percepción, que desemboca en la aprehensión del objeto, al que se produce cuando Menelao captura a Proteo, el cual pasa por una serie de metamorfosis, hasta que al fin hace entrega de su verdadera apariencia (la de un viejo) ${ }^{7}$. Comenzaré pues por recordar algunas frases de Weil que permiten entrar en materia:

No hay solamente, en el acto de percibir, el conocimiento de las cualidades, de las formas, de las distancias; hay también esto que aprehendo en el espacio. ¿Qué es el espacio? ¿Una simple manera de percibir, o Proteo obligado finalmente a no eludirme más? Que yo perciba el espacio, no quiere decir simplemente que yo perciba, por ejemplo, este gato en el suelo entre este libro y yo; un movimiento, sea del gato, sea mío, basta para destruir esa relación, que no es sino relación de distancias. El espacio no se ve por ello cambiado: no depende ni de las distancias, ni de los tamańos, ni de las formas de los objetos; sean cuales sean, siempre él se extiende a mi alrededor, en todo lugar semejante a sí, indiferente a la manera en que formas, distancias, cualidades hallan lugar en él. Porque cada cualidad, cada tamaño, cada distancia, cada forma es signo de una parte del espacio que no es ni cualidad, ni tamaño, ni forma. (WEIL, 1988, p. 124).

\footnotetext{
7 Ver De la perception ou l'aventure de Protée (1929) y el conjunto de los textos en vista del artículo que en la edición de las CEuvres complètes se intitula: Autour de "Protée" (WEIL, 1988, p. 121-139).
} 
Quisiera desde ya mostrar que para Weil hay una relación profunda entre percepción y espacio, y que la filósofa tiene en mente la concepción kantiana del tiempo y el espacio como intuiciones a priori $i^{8}$. En efecto, ella alude a un espacio que puede ser considerado en dos sentidos: por un lado, como una forma de percibir que está dada antes de toda percepción empírica y que es fija en nosotros", a saber el espacio como intuición a priori en el sentido kantiano, es decir, nuestra capacidad o intuición fundamental ya predeterminada en nosotros que nos permite abrazar todos los fenómenos espaciales; y por otro lado, el espacio como fenomenalización de entes particulares (es decir la manifestación misma de esos fenómenos que envolvemos mediante nuestras intuiciones a priori que son el tiempo y el espacio). En este caso particular, cuando Weil habla de Proteo, se refiere a los fenómenos que nos son dados a través de nuestra percepción sensorial ${ }^{10}$. La confrontación con Proteo es nuestra confrontación con un fenómeno dado. Ella señala que cuando percibimos un fenómeno, éste se muestra fugitivo. Así, en un primer momento, al percibir cualquier cosa, no sabemos exactamente a qué fenómeno específico estamos asistiendo, si no es a través de una lucha entre ese Proteo que huye y este yo perceptor que intenta aprehenderlo:

¿Pero cómo es que logro aprehender el espacio? Porque ciertamente Proteo no se me aparece en primera instancia como extenso; y hay que cuidarse de tomar por el espacio esta suerte de tapete abigarrado, extendido frente a mí, que me parece ofrecerse inmediatamente a la vista, o las resistencias que se ofrecen al tacto. Proteo se presenta al espíritu como una emoción, luego otra, luego otra; cada una de esas emociones viene sin ser llamada o producida por mí, y sin serme no obstante extranjera. Es así como a veces, si un fruto se ofrece a mi vista, lo he arrancado y llevado a mi boca incluso antes de darme cuenta de ello. (WEIL, 1988, p. 124-125).

\footnotetext{
${ }^{8}$ Müller anota precisamente con razón que "Desde una perspectiva meramente kantiana ella entiende el tiempo como una determinación trascendental del conocimiento y de la acción humana. El tiempo es una instancia de orientación trascendental para el hombre." (MÜLLER, 2001, p. 92).

${ }^{9}$ Como lo anota M. Janiaud (2002, p. 12): "El espacio es el invariante que sostiene las cualidades y las formas, pero que por sí mismo no tiene nada que significar."

${ }^{10}$ Es patente que en sus primeros años Simone Weil limita el problema del tiempo y el espacio a su dimensión experimental en el sentido kantiano, y que toda consideración mística (en el sentido de un conocimiento por intuición intelectual, excluido de tajo por Kant) no aparecerá en la obra de nuestra autora sino hasta los ańos 30. Dicho esto, compartimos la idea de Pascal David, cuando dice que la Simone Weil de la última época conserva el proyecto de hacer de "[...] lo absoluto una ciencia experimental." (DAVID, 2012, p. 30).
} 
El fenómeno es volátil, somos tomados por asalto por emociones de las que no sabemos si vienen de nosotros mismos, del fenómeno, o de otra parte: sentimiento de extrańamiento y de familiaridad a la vez. Weil muestra que el individuo, en esta crisis que se produce antes de la aprehensión del espacio y el objeto, se ve sumergido por un bombardeo de emociones y deseos (viendo un fruto, solamente porque se le desea, uno se piensa ya comiéndoselo, y esto incluso antes de habérsele acercado, ya que nos anticipamos por el deseo a la posesión real del objeto). Es como si el fenómeno se nos escapara y que lo persiguiésemos con nuestro entendimiento, que intenta disciplinar nuestra percepción. Ahora, cuando logramos capturarlo, el fenómeno nos presenta su naturaleza de objeto. Éste es el Proteo obligado finalmente a no eludirme más. Proteo es movedizo en el espacio. Ahora bien, si es movedizo es porque en nuestra percepción este espacio movedizo (el conjunto de los fenómenos que interactúan) está sometido a un doble cambio: el movimiento fenoménico (de cierto modo externo) y el movimiento imaginativo (interno). Proteo es la envoltura que camufla el objeto a través del tejido de nuestras emociones, del conjunto de las imágenes que están ligadas a nuestros deseos y a nuestras aversiones, y por ende al estado actual de nuestro cuerpo. Con el fin de comprender mejor esta concepción de Weil, detengámonos unos instantes en un pasaje de Kant que trata sobre la cuestión de la percepción y del objeto en el espacio, y que me parece ha influenciado determinantemente el pensamiento de la filósofa:

No hay $[\ldots]$ por fuera del espacio ninguna otra representación subjetiva y relacionándose a algo exterior que pueda ser llamada objetiva a priori. [...] con la representación del espacio ellas (las representaciones) poseen esto de común que es que pertenecen solamente a la constitución subjetiva de la sensibilidad, por ejemplo de la vista, [...], a través de las sensaciones de los colores, $[\ldots]$, los cuales sin embargo, no siendo más que sensaciones y no intuiciones, no hacen conocer en sí mismas objeto alguno, por lo menos $a$ priori. [...] lo que llamamos objetos externos no corresponden [...] sino a simples representaciones de nuestra sensibilidad, de los que el espacio es la forma, pero cuyos verdaderos correlatos, es decir la cosa en sí, no es en absoluto conocida por ese medio ni puede serlo. (KANT, 2001, p. 124-125).

Si bien el espacio no es una característica de las cosas en sí (de las que nada sabemos a través de la experiencia), él es no obstante la forma de todos los fenómenos. A partir de ahí podemos comprender mejor lo que señala Weil en lo que concierne a las emociones ligadas a las imágenes multiformes 
de Proteo: ellas pertenecen a nuestra subjetividad. Además, debemos decir que ningún fenómeno nos puede ser dado si no nos es dado, previamente, el espacio como intuición para percibirlo. Lo vemos, Weil retomó de manera muy fiel la reflexión que hace Kant que concierne a la diferencia entre nuestros elementos subjetivos propiamente sensoriales, susceptibles de diferir de un individuo a otro, y la homogeneidad de la percepción espacial como dato fundamental de la objetividad de la percepción. Sin embargo, no se puede negar que hay una particularidad en el acercamiento de Weil, ya que su Proteo parece diferir de la concepción kantiana en que, en la percepción, la emoción ligada a las imágenes percibidas precedería la aprehensión del espacio. Hay que señalar que esto podría parecer una contradicción respecto a la propia concepción kantiana de Weil, pues para que la cosa pueda ser percibida por nuestros sentidos externos, ella debe poder sernos representable en calidad de fenómeno. Intentaré elucidar mejor esta aparente contradicción: en la concepción weiliana, cuando inmovilizamos a Proteo, lo despojamos de su carácter movedizo y percibimos en él el objeto que nuestros sentidos no pueden en lo absoluto aprehender por sí solos. Nuestro entendimiento, vía nuestras intuiciones a priori, logra aprehender el objeto. Es así que, cuando Weil habla de la destrucción de esta relación, que no es otra cosa que relación de distancias, ańade que el espacio no es para nada modificado, porque nada en nuestra intuición a priori se ve alterado (nuestra capacidad para intuicionar los fenómenos y los objetos en el espacio permanece indemne). Lo que se destruye y modifica es la relación de los fenómenos entre sí. Al alejarnos del gato, modificamos la distancia inicial entre los dos, pero no destruimos en lo más mínimo la capacidad para aprehender las distancias entre el gato y nosotros, sean cuales sean. En efecto, este espacio en el cual los fenómenos nos parecen tomar lugar, no está constituido por ellos. Ese espacio, que es la condición de posibilidad para que los fenómenos espaciales tomen lugar, es independiente de las relaciones que éstos mantienen entre sí. Es por ello que ese espacio nos parece estar ahí, haya o no objetos en él. Nos parece ser independiente de ellos (incluyéndome a mí mismo entre éstos en mi calidad de objeto que mantiene relaciones espaciales con otros objetos). En este caso en particular, podemos observar que la filósofa, al mostrar esta diferencia entre Proteo (en su calidad de fenómeno huidizo que esconde su objetividad) y el espacio, como manera de percibir, retoma en cierta medida el pensamiento de Descartes, quien influyó a Weil ${ }^{11}$, particularmente

\footnotetext{
${ }^{11}$ Julien Molard (2004, p. 22) subraya que Simone Weil tenía, desde sus ańos de profesora, la certeza de que Descartes constituía uno de los autores clave para formación académica de sus estudiantes.
} 
a propósito de su reflexión sobre lo extenso y los cuerpos extensos en las Regulae:

Por extensión entendemos todo lo que posee longitud, largura y profundidad, sin preguntarnos si se trata de un cuerpo verdadero o solamente de un espacio; [...] no se designa aquí por extensión nada que sea distinto y separado del sujeto mismo [...]. [...] uno puede evidentemente persuadirse, por ejemplo, que si uno reduce a nada todo lo que es extenso en la naturaleza, no es contradictorio que la extensión misma continúe existiendo sola, se hará no obstante uso, para llegar a esta representación, no de una idea corporal, sino del solo entendimiento que se equivoca en su juicio. [...] si uno piensa con atención en esa imagen misma de la extensión, que uno intentará forjar en su fantasía en el curso de la operación, se constatará en efecto que uno no la aprehende en lo absoluto desprovista de todo sujeto, sino que uno la imagina de una manera diferente a como se la juzga. (DESCARTES, 2002, p. 166-167).

Acá Descartes señala que una cosa es representarse la extensión y las cosas extensas, y otra es considerarlas con el entendimiento. Nos muestra que hay que tener claro que cuando se trata de representarse la extensión y las cosas extensas, ellas son indisociables. La extensión sola no puede ser imaginada; el espíritu imagina siempre un sujeto extenso. Sin embargo, solamente el entendimiento puede separar la cosa de su extensión concibiéndolo, pero no representándoselo por medio de imágenes, ya que el entendimiento no tiene en sí mismo la capacidad de suscitar imágenes. Ahora bien, la imaginación que tiene por función la producción de las imágenes, no puede en absoluto hacer representable la extensión sin representarse al mismo tiempo una cosa extensa. Así, Weil toca pues a esa misma dificultad que evoca Descartes en las Regulae; son mis sentidos los que perciben cosas extensas, pero ninguna imagen (que sea producto de la sensibilidad o de la imaginación en general ${ }^{12}$ ) puede representar la sola extensión en general, ni aquella correspondiente a un cuerpo extenso particular. Por ende, uno no aprehende en lo absoluto ni imágenes de la extensión en la abstracción, ni imágenes que nos vengan de la percepción sensorial, puesto que uno siempre ve cuerpos extensos. Weil

\footnotetext{
${ }^{12}$ Es de destacar la observación que hace Descartes en la Meditación Quinta sobre la realidad de las propiedades geométricas de las figuras imaginadas a pesar de que no existan en la actualidad de la materia expuesta a la percepción: "[...] puedo formar en mi espíritu infinidad de figuras, de las que no se puede tener la más mínima sospecha de que nunca antes hubieran caído bajo mis sentidos, y sin embargo no dejo de poder demostrar diversas propiedades que atañen a su naturaleza [...] que deben necesariamente ser verdaderas, puesto que las concibo claramente." (DESCARTES, 1953, p. 311).
} 
señala también ese error del entendimiento al que hace referencia Descartes: el entendimiento puede equivocarse si toma la extensión por la cosa extensa. Lo vimos, para no caer en este error es preciso, previamente, tener presente que uno no puede percibir ninguna representación de la extensión en sí misma, si no es incorporada a cuerpos extensos. Y luego, hay que saber que si bien nuestras representaciones no pueden sino presentarnos cuerpos extensos y no la extensión en sí misma, en nuestro espíritu se halla una facultad intelectual (el entendimiento) que es la única que puede realizar la separación. El espacio no es separable de las cosas extensas si no es por medio de una operación del entendimiento, pero debemos ser conscientes que ninguna representación puede traducir esta inteligibilidad, ya que la imaginación no puede sino representarse cuerpos extensos. Descartes y Weil indican que hay que ser conscientes de estas dos facultades (entendimiento e imaginación), las cuales abordan diversamente la realidad espacial. Hechas estas consideraciones, podemos volver ahora con más claridad a la especificidad del proceso weiliano de la aprehensión espacial que se produce en la percepción de una cosa extensa. Siguiendo la concepción kantiana de Weil, para que la cosa sea percibida por nuestros sentidos externos, ella debe poder sernos representable en calidad de fenómeno. Ahora bien, nada puede sernos representable por nuestros sentidos si no es por medio del espacio, que es nuestra intuición a priori. Por consiguiente, para que todo fenómeno sea aprehendido por nuestros sentidos externos, él debe ser captado como un cuerpo extenso. Pero Weil nos dice que Proteo es primero una seguidilla de emociones, y solamente después, cosa extensa. ¿Contradicción, oposición a Kant? No. Ella esta ciertamente señalando que Proteo es percibido en su condición de fenómeno antes de que su naturaleza de objeto sea revelada. Pero discierne que el espíritu toma cierto tiempo para comprender que la cosa percibida es cosa extensa. Así, el espíritu capta, desde el inicio, la realidad espacial del cuerpo percibido, como condición para experimentar la emoción y el deseo al que viene ligada, pero aún no es consciente de ello. Así, en el lapso que separa el momento del encuentro de nuestros sentidos con la cosa (que Weil dice ser el de la sucesión de las emociones) y el de la aprehensión intelectual de la espacialidad del cuerpo percibido y del espacio en general, habría un proceso de toma de consciencia de la espacialidad, y no un inicio de aprehensión ésta. Entre el encuentro y la intelección de la espacialidad de la cosa percibida hay un tiempo de expansión de la imaginación y, solamente más tarde, un tiempo de la acción del entendimiento. En efecto, este último se hace consciente de la cosa percibida en su calidad de cosa espacial. Cuando el entendimiento actúa acorde 
a las reglas de la intuición a priori del espacio, se opera una limpieza progresiva de las imágenes que vienen de nuestra imaginación subjetiva, que se habían proyectado sobre el fenómeno percibido. Cuando el entendimiento actúa de semejante forma y aprehende lo que hay de objetivo en la cosa percibida, la actividad de la imaginación pasa a un segundo plano. Así pues, anclada en la perspectiva kantiana, Weil estima que la sola percepción de una cosa a través de los sentidos implica la existencia de una capacidad para percibir la cosa en el espacio y el tiempo; por ende, el espíritu aprehende a priori la espacialidad de la cosa, si bien la acción del entendimiento consciente no viene sino tras haber pasado por la etapa de la imaginación movediza, que inunda nuestra percepción con imágenes diferentes. ¿`Pero cómo interpretar esta actividad de nuestra imaginación? ¿'Se debe considerar que su rol es puramente parasitario, o incluso, que no está ahí más que para suscitar confusión y extraviar nuestro juicio? Por el contrario, creemos que Weil tiene una concepción cartesiana en lo que concierne a la imaginación, y podemos suponer que para ella, si la imaginación es frecuentemente engańosa como lo anota en la cuarta parte del Discurso del Método ${ }^{13}$, es también un auxiliar del entendimiento, como lo expone Descartes en las Regulae. La filósofa nos hace ver que esas imágenes y emociones no pertenecen al objeto, sino que nuestro cuerpo no puede impedirse proponérnoslas como tentativas para aprehender el objeto. ¿No se debe comprender con esto que Weil hace alusión a la imaginación como capacidad mnemónica? ¿Porque de dónde salen las imágenes si no las hemos ya visto? Tomadas en este sentido, esas imágenes y emociones tendrían entonces un nexo con la memoria. Ésta enviaría imágenes que no convienen al principio, puesto que el espíritu tiene en ese momento muy pocos datos para conocer el objeto. Así, avanza en su identificación de la cosa percibida por medio de un tanteo que se traduce por la proyección de imágenes aproximativas, y por consiguiente inadecuadas. Desde esta perspectiva, las imágenes y emociones serían también un instrumento (ciertamente puramente subjetivo) para identificar la cosa percibida. Continuando en este camino, podemos decir que el Proteo cambiante es una etapa necesaria para identificar la cosa percibida. Así, el tiempo intervendría en esta localización que se desarrolla entre el encuentro sensorial y la intervención consciente del entendimiento. Vimos que este último opera una neutralización del flujo cambiante de las imágenes, hasta

${ }^{13}$ Descartes, tras indicar que los sentidos son frecuentemente engañosos, va más lejos al añadir que todo lo considerado por la mente puede ser concebido como ilusorio: "[...] me resolví a fingir que todas las cosas que me habían entrado en el espíritu no eran más verdaderas que las ilusiones de mis sueños." (DESCARTES, 1953, p. 147). 
el punto en que solamente quedan unas cuantas, las que sitúan de la manera más adecuada la cosa percibida en nuestra capacidad para especializar. Esto significa entonces que el entendimiento se hace consciente de la espacialidad de la cosa. Ahora, esta toma de consciencia de una espacialización que está ya ahí, si bien se ve invadida por imágenes, requiere cierto tiempo para realizarse. Dicho de otro modo, se requiere de cierto tiempo para situar las imágenes adecuadas (las que son escogidas) en nuestra intuición espacial de los cuerpos extensos o fenómenos, porque, en primera instancia, nuestra percepción se ve estorbada por las imágenes subjetivas que nuestra imaginación proyecta sobre la cosa percibida. Es cuando llega la plena aprehensión de la espacialidad del fenómeno percibido que se produce la adecuada identificación del objeto:

Apenas el espacio se ha formado, Proteo es vencido. Porque a pesar de que su cuerpo, doblando y desdoblando sus más íntimos tejidos, continúa mimetizando, según la ocasión, al león, a la pantera, al árbol, Proteo no puede ya fingir ser árbol, bestia o agua: lo he obligado finalmente a decir la verdad, es decir a no decir nada. (WEIL, 1988, p. 126) .

Weil muestra así que la verdad de Proteo es el objeto que esconde el fenómeno no aún identificado. Ahora bien, la identificación se produce cuando su espacialidad se nos ha hecho manifiesta. Proteo cesa de hablar (cambiar de forma) cuando uno lo inmoviliza por medio de la comprensión espacializante que está ya en nosotros, pero que todavía no ha podido envolver al objeto y las características espaciales que le son particulares. Obligamos a Proteo a no decir nada cuando nuestra capacidad para aprehender el espacio se ha hecho adecuada respecto a la naturaleza espacial del objeto.

\section{Proteo hace entrega Del TIEMPo}

Llegamos acá a un punto de vital importancia en esta investigación: el Proteo weiliano no solamente hace entrega del objeto cuando el ente perceptor logra inmovilizarlo; esa enigmática creatura, cuya naturaleza es la metamorfosis, nos da además, mientras no lo hemos obligado a aquietarse, la experiencia del movimiento, y por ende, del tiempo. En este sentido, es legítimo interpretar de la siguiente forma el pensamiento weiliano: si el fin de la percepción es el espacio (su percepción plenamente consciente), el medio para alcanzarlo (al espacio) es el tiempo. Y es que antes de que se realice el paso de adecuación entre ente perceptor y objeto percibido, Proteo nos sumerge en el tiempo, es decir en el 
reino de lo sucesivo. Una vez nuestra aprehensión espacial es ejercida, salimos de la sucesión y entramos en la inmediatez de las realidades espaciales, que se han hecho conscientes. Cierto es que, en realidad, nunca salimos del tiempo, pues es en éste que consideramos las realidades espaciales del objeto. Pero dicho esto, hay no obstante un carácter de inmovilidad, pues en la aprehensión del espacio nada cambia en las realidades espaciales, que a partir de ahora han sido aprehendidas e interiorizadas en nuestro espíritu, por aquello que en nosotros establece las relaciones espaciales. Porque se trata de una capacidad que, como ya se ha anotado, reside en nosotros (en tanto que intuición a priori), y que solicitamos para considerar un fenómeno particular en un momento dado, es decir en el momento de la percepción. Intentamos así aprehender lo que hay de permanente en sus relaciones, y es así que se da una puesta en práctica de las reglas espaciales que residen ya en nuestra intuición. Este conjunto de reglas nos dará una idea permanente del fenómeno, incluso si este se transforma o viene a ser destruido. Es así como cristalizamos en nuestra idea la imagen que estaba ya en el momento de la percepción, y sacamos en limpio las susodichas reglas espaciales ya aprehendidas a priori en nuestra intuición, conforme a la imagen espacial conservada. El fenómeno puede cambiar, pero no el objeto, que no es otra cosa que el conjunto de las reglas espaciales objetivas, acordes con el estado del fenómeno tal y como lo percibimos antes del cambio. Es así como, respecto a nuestro entendimiento, solamente cambiarán las realidades externas, a saber, las relaciones de distancia que mantienen los fenómenos entre sí, porque son solamente ellos los que pueden cambiar y no las reglas que rigen su constitución espacial. Es lo que entiende Weil al decir que Proteo continúa plegando sus formas corporales, incluso si ya lo he vencido, si bien continua a mimetizar, según la ocasión, al león, la pantera, el árbol, Proteo no puede ya fingir ser árbol, bestia o agua. Porque lo he vencido para mí, o dicho de otro modo, lo he derrotado en la comprensión de las relaciones espaciales que lo constituyen en el instante en que lo percibo, y no en sí mismo en su calidad de cuerpo externo, ya que sus relaciones pueden a todo momento cambiar respecto a sus propias partes y respecto a las partes de otros cuerpos que interactúen con él. Al decir que Proteo intenta aún mimetizar, si bien ya se le ha plenamente aprehendido, Weil puede estar pensando también en el hecho de que nuestra capacidad para producir imágenes continúa sugiriéndonos nuevas imágenes sin lograr hacernos perder la aprehensión del objeto. Por consiguiente, no podemos ya ser engañados, pues desde ahora serán percibidas paralelamente al objeto, y aprehendidas bajo el auspicio de la plena conciencia de su realidad de imágenes vacías de objetividad, es decir que no tienen existencia alguna por fuera de mi imaginación (creadora o productora de recuerdos). Dicho esto, volvamos a la cuestión de los cambios 
continuos que se producen, no ya en el flujo de las imágenes proyectadas por nuestra imaginación, sino en la exterioridad de los fenómenos. Experimentamos que esos cambios de las cosas exteriores respecto a sus partes y respecto a las demás cosas no dependen de nosotros, podemos obligar a Proteo a cesar de moverse ahí hasta donde depende de nosotros, o dicho de otra manera, podemos restringir nuestra propia imaginación y emociones, aprehendiendo la espacialidad de la cosa percibida, que de este modo nos revela su naturaleza de objeto. Esto implica para Weil que el espacio tiene esta propiedad, es decir que revela la objetividad del mundo. Ahora bien, las cosas percibidas en el espacio, al volverse objetos, se comportan de tal modo que se nos presentan como esencialmente otras, separadas de mí como sujeto, debido a su objetividad infranqueable, y también por el hecho de que yo no soy el espacio, sino que me percibo a mí mismo como un objeto que se desplaza en él. Por consiguiente, el mundo externo no puede aparecer sino como un conjunto de cosas yuxtapuestas, esencialmente extranjeras respecto a mí mismo. No puedo estar a todo momento en todo el espacio, sino que debo desplazarme para ir de un lugar a otro. El espacio, en cierto sentido, puede ciertamente ser mi capacidad perceptiva (intuición a priori en el sentido de Kant), pero me revela un mundo que, porque no puede ser percibido de otra forma que no sea espacializada, está esencialmente separado de mí. Hay que decir que esta separación se establece desde dos puntos de vista: por un lado, estoy estructuralmente separado de él si lo considero como unidad (él se presenta como un espacio que no soy yo y en el que me muevo, como en medio de una otredad); y por otro lado, estoy incesantemente separado de él si considero mi relación con sus partes (cuando me muevo en él lo hago a partir de una de sus partes hacia otra). Vamos a un pasaje ilustrativo:

Pero la idea de distancia, a partir del momento en que la aplico al mundo es también ambigua de otra manera. Porque la idea de distancia expresa que ningún desplazamiento para mí es inmediato, que en cualquier lugar que yo desee estar, no puedo inmediatamente dirigirme hacia él; pero lo que me impone esa ley, es un mundo que resiste a toda dirección que yo pueda tomar, porque la yuxtaposición es la única relación que ahí es posible. Como la distancia es una relación entre cosas separadas, el mundo, en tanto que está definido por la yuxtaposición, me impone la distancia, pero para sí mismo no la acepta ; si nada para mí es inmediato, es porque en el mundo, en cierto sentido, no existe sino lo inmediato. (WEIL, 1988, p. 146).

Este pasaje nos conduce a hacer dos observaciones. La primera: el espacio se me presenta como otredad estructural, es decir que estoy obligado a alcanzar 
lugares diferentes del mundo a través de la mediación de lugares intermedios. Él se me presenta como una unidad, pero ésta no coincide con la mía, porque para ser uno con el mundo yo debería separarme en una infinidad de partes, para alcanzar todos sus lugares al mismo tiempo. Ahora bien, yo no puedo sino estar en un solo lugar a la vez, no puedo fundirme con la unidad del mundo. Por todo lo anterior, la unidad de éste me resulta extranjera en dos momentos: primero, como conjunto esencialmente separado de mí (porque mi unidad está separada de la suya no puedo coincidir con él); y luego como unidad que no es solidaria consigo misma, es decir que ella me parece ser divisible al infinito. Sus diferentes lugares no son el mismo lugar, él es una unidad compuesta por una infinidad de lugares.

La segunda observación: Weil parece plantear la inmediatez del mundo como mera hipótesis. Se le puede interpretar como el hecho de que si el mundo es considerado como objeto, en su unicidad él ya está en sí mismo. Dicho de otro modo, en su condición de uno (y no en su condición de ser divisible) no puede estar sometido a la espacialidad respecto a sí mismo. Weil plantea así la hipótesis de una unicidad simple y por ende no espacializable. Esto significa una unidad por fuera del tiempo, pero también, y esto es de poner en relieve, como fuera del espacio. $\mathrm{O}$ en otras palabras, se trata de un mundo que no está sometido a la división que me da la espacialidad tal y como la concibo, y que atribuyo al mundo de los fenómenos. Ese mundo en sí sería ajeno a la mediación, la cual es la realidad que nos compete. Él estaría en sí mismo inmediatamente, y por ende sería ajeno al espacio y al tiempo. Pero subrayémoslo, Weil no evoca esto sino a título de hipótesis, puesto que como Kant, ella considera que uno no puede saber nada de las cosas en sí, por lo menos si aceptamos que nuestras intuiciones a priori son el espacio y el tiempo, y por ende que toda cosa percibida no puede sernos dada si no es en dicho marco. Acabamos de ver cómo la figura de Proteo, como acontecimiento perceptivo, es el centro de gravedad entre la inteligibilidad del espacio y la del tiempo. A este propósito visitemos pues un pasaje clave de Weil (1988, p. 152-153):

La distancia es una idea que no pertenece tanto al espacio como al tiempo, si bien solamente la extensión nos impone, entre nuestro objeto y nosotros, una distancia; de ahí esta formulación asombrosa «el tiempo es la medida del espacio», o esta otra formulación, en el fondo equivalente: «El número es el esquema de la cantidad". ${ }^{14}$

\footnotetext{
${ }^{14}$ Los editores de las Obras completas de Gallimard atribuyen la primera cita a Jules Lagneau in Célèbres leçons et fragments, al fragmento 51, la segunda cita la atribuyen a Kant in Crítica de la Razón pura I, $1^{\text {ìra }}$ división, libro II, chap 1, "Del esquematismo de los conceptos puros del entendimiento".
} 
Lo vemos, entre las dos expresiones tomadas respectivamente de Lagneau y de Kant, Weil ve una equivalencia. En otros términos, podemos decir que ella considera el tiempo como una suerte de patrón de medida cuya inteligibilidad nos es previa a toda intuición del espacio, y que nos permite aprehenderlo. También comprendemos que se trata de una especie de unidad o capacidad para aprehender la cantidad. El tiempo parece ser para la filósofa una instancia que mide lo medible, que estructura lo que puede ser numerado o cuantificado. En síntesis, se trata de algo que permite ordenar, organizar lo que es extenso, disperso en un desorden aparente para el espíritu. Pero además de esta relación con el espacio, ¿cuál es para Weil la especificidad del tiempo respecto a sí mismo? ¿Así como estructura al espacio, el tiempo se envuelve a sí mismo? $\mathrm{O}$ en palabras más claras, ¿el tiempo es una manera de ordenar el tiempo? Veamos lo que dice la filósofa: "El tiempo es [...] esencialmente la relación entre el presente y el futuro; el pasado no es pensado sino por reflexión, y está, él también, dirigido hacia el futuro. Desear volver al pasado no tiene sentido; querer (vouloir), es voltearse hacia lo que debe ser." (WEIL, 1988, p. 149).

Weil pone énfasis en el tiempo presente. Ella marca su importancia como siendo el tiempo realmente vital en la vida humana. Si Weil hace entender que el tiempo sería la relación entre presente y futuro, es porque ella establece una neta diferencia entre deseo y voluntad. El deseo, estando ligado a todo lo posible e imposible, estaría pues habitado por una temporalidad esencialmente imaginaria, pudiendo anclarse o no en la realidad. Mientras que la voluntad sería una aspiración más cercana a lo realizable en medio de lo posible. Así, el deseo puede voltearse libremente tanto hacia el pasado como hacia el futuro, (incluso si es completamente insensato hacerlo hacia el pasado, tratándose entonces del sentimiento de la ańoranza o la nostalgia), estando en todo caso esencialmente separado de lo posible. Al opuesto, la voluntad, si bien está abocada hacia lo real, no puede mirar sino hacia el futuro. No es aplicable al pasado, porque al pretender modificarlo, se transformaría instantáneamente en deseo insensato. El vínculo íntimo entre voluntad y futuro se debe al hecho de que el futuro es la temporalidad de lo que puede ser, mientras que la temporalidad del pasado, en cierto sentido (puesto que ya no está ahí) está ya plenamente anclada en lo que fue y no puede modificarse ${ }^{15}$.

\footnotetext{
${ }^{15}$ A este respecto, es útil observar que en uno de sus trabajos, Heinz Robert Schlette (2001, p. 78) hace énfasis en la preocupación que tuvo siempre Simone Weil por el pasado y en esa dirección la dificultad de hablar de una fílosofía weiliana de la historia, en contraposición a una filosofía del pasado. A juicio nuestro es una posición difícil de sostener si pensamos en la crítica a la historia que hará Simone Weil
} 
El futuro es el tiempo en donde los hombres no han jugado aún sus cartas. Si el futuro es libertad por venir, solamente el presente es el tiempo de la libertad efectiva, la única real. Esta libertad no tiene sentido sino en el marco de las perspectivas futuras, porque toda acción en el presente se hace en vista de un cambio querido, que eventualmente verá la luz en el futuro. Ahora bien, todas nuestras acciones pasadas han sido, en su presente, realizadas con miras a cambios futuros. Es de hecho lo que deja entender Weil al decir que el pasado está dirigido hacia el futuro. La voluntad es entonces, ante todo, un impulso hacia la transformación libre de lo que puede ser transformado, es decir únicamente hacia el futuro:

Uno no puede pensar el pasado como si no fuera nada; uno no puede ni siquiera imaginárselo como si nunca hubiera sido. En cierto sentido el presente envuelve el futuro porque lo determina; en otro cierto sentido contiene todo el pasado como siendo su desarrollo. También el pasado, que a cada instante parece no haber existido sino por lo que era entonces el futuro inmediato, y que no era en efecto percibido sino en vista de conocer este futuro, ese pasado aparece como simplemente abstracto respecto al presente ; de manera que el espíritu se asombra de que él no haya jamás podido existir. Por otro lado el pasado es irreparable; lo que incluso no tendría sentido alguno si él no estuviera por sus huellas, enteramente contenido en el presente. (WEIL, 1988, p. 302).

Weil muestra que la esencia del pasado es problemática, porque contiene dos aspectos que parecen contradictorios: por un lado parece no tener consistencia, a pesar de que se erige como la condición del futuro. Ahora bien, en la medida en que no podemos considerar esta condición sino en el presente que se abre de manera ininterrumpida hacia el futuro (el cual no se revela sino progresivamente), no podemos nunca percibir directamente ese pasado. Sabemos que éste es la condición del futuro que, segundo a segundo, se deja ver por nuestros ojos. Pero si dada esta situación, es cierto que el futuro se deja ver al volverse presente, el pasado, en lo que le respecta, jamás se deja percibir directamente. Es únicamente cuando uno pierde ese presente (cuando ya no lo tenemos frente a nuestros ojos) que se vuelve pasado; este último es pues, para siempre, no observable. Por otro lado, el ser del pasado se muestra con toda su consistencia, ya que cada instante presente es la prueba de que algo lo ha suscitado. Se puede afirmar que el

en sus textos sobre el colonialismo, en los que abordará el problema de establecer la credibilidad de la historia, cuando es escrita por los vencedores. 
presente no sería posible sin que el pasado haya puesto su condición. Así, de la misma manera que el presente determina el futuro, el pasado determina el presente y por consiguiente, en última instancia, el futuro. Recíprocamente, en la medida en que el presente contiene el pasado, estamos en derecho de concluir que el futuro contiene no solamente el presente, sino también el pasado. Porque a pesar de que ese futuro no sea todavía, se le puede pensar como necesariamente por venir, puesto que ya están puestas la totalidad de las condiciones de su acontecer, es decir, ya se le han determinado las condiciones de su despliegue. Así es como su ser por venir puede ser pensado como teniendo ya una realidad, incluso si, en cierto sentido, ésta no es todavía. Estamos, por consiguiente, frente a una contradicción de gran calado, puesto que ese porvenir que no es, a propiamente hablar, todavía, no puede contener nada. Por otro lado, puesto que ya ha estado determinado en la totalidad de su despliegue, pues está ya contenido en el presente, es legítimo afirmar que contiene ese pasado, que no obstante ya no está en el instante presente, y todavía menos en el tiempo por venir. Dicho esto, si aceptamos que ese futuro contendrá el pasado, ¿a través de qué podría hacerlo, si no es a través del presente, que establece el vínculo entre pasado y futuro? Como lo señala Weil, si el tiempo es esencialmente una relación entre el presente y el porvenir es porque el presente es relación entre el porvenir y el pasado. Y esto incluso si el pasado es solamente pensado por reflexión. Porque si bien parece abstracto con relación al presente, el pasado deja huellas irreparables en este mismo presente. Sin embargo, la relación entre pasado, presente y porvenir no puede ser considerada como una libre simetría, en donde uno puede poner arbitrariamente pasado y porvenir según nuestro buen parecer. Es para mostrar bien esta relación, la cual se desarrolla en un solo y determinado sentido, y por consiguiente no arbitrario o libre, que a este propósito Weil habla del carácter dirigido del tiempo:

El tiempo está dirigido por definición [...]. Se dice frecuentemente que es irreversible; pero esta imagen parece invitarnos a volver atrás, como si las nieves de antaño estuvieran en algún lugar, pero inaccesibles para mí [...]. Metáforas han dado lugar a la ficción de la máquina para viajar en el tiempo, sueńo humano [...] que con dificultad me impido formar [...] esas metáforas son falsas. (WEIL, 1988, p. 143).

El pasado es condición del presente y del porvenir, y no al revés. A pesar de esto, aparece de forma bastante sorprendente que, a pesar de que el 
pasado sea la única cosa que nos es dada con total certidumbre, nos parece que pierde su importancia, y de cierta manera su realidad respecto a un presente que nos envuelve enteramente a cada instante, y también respecto a un porvenir que es susceptible de ser vivido, es decir, de volverse presente. A partir de esta reflexión sobre el pasado, debemos ahora abordar un aspecto importante que le es inherente. Pues si bien es a partir del estado pasado de las cosas que recibimos su estado presente, ese tiempo pasado se borra de nuestra vida por dos razones : primero, la más evidente, a saber que cuando el tiempo pasa, yo no puedo retener el estado material pasado de las cosas. Y luego, una razón menos evidente, que es que mi pensamiento, es decir eso mediante lo cual considero el estado pasado de las cosas, está también expuesto al flujo del tiempo. Veamos que nos dice Weil (1988, p. 74) a este respecto:

Pero la reflexión sobre el tiempo es quizá la más difícil que sea, porque, por más lejos que podamos aprehender el tiempo, parece que es ese tiempo el que nos lleva consigo. Yo quiero detenerme, y mirar fluir el tiempo como se mira fluir un río; pero no lo puedo; mientras que pienso, el tiempo también se lleva consigo mi pensamiento.

Weil señala acá dos dimensiones: una que nos permite aprehender el tiempo como un objeto, y por consiguiente, a partir de esa aprehensión, capturar algo de él, a saber su idea; y otra en donde el tiempo es más acción real que idea, es decir, cuando mediante su influjo efectivo y concreto, dicho tiempo nos envuelve, y al hacerlo, hace que nos movamos con él y nos lleve consigo. Weil subraya entonces que ese tiempo se lleva consigo el pensamiento, es decir que la retención de mi idea está, ella también, expuesta a la acción del tiempo. Así, a pesar de la tentativa del espíritu para aprehender el tiempo como objeto, que evocamos más arriba, esta aprehensión se revela frágil frente a la acción movediza del tiempo, porque esa acción se remite tanto a la materialidad de las cosas, como al pensamiento de los hombres y al conjunto de sus facultades mentales. El tiempo nos obliga a desprendernos de su idea por el hecho de que él se lleva todo consigo en su flujo, tanto nuestras realidades corporales como las espirituales ${ }^{16}$. Cuando Weil dice que incluso si yo quiero detenerme para mirar fluir el tiempo como un río y no

\footnotetext{
${ }^{16}$ Casper muestra claramente la relación entre el sentimiento de posesión y la idea del tiempo personal: “[...] jamás mi tiempo es el tiempo. Weil explica esto [...] mediante la diferencia entre el tiempo que yo paso en el trabajo en cadena y el que paso al mirar una pintura de Giotto. Uno puede preguntarse
} 
lo puedo, da a entender que nada en mí, ni mi cuerpo ni mis ideas pueden detenerse ni retener lo que buscan asir, y entre esto no es excepción la acción y la idea del tiempo. Toda idea y todo recuerdo que persiga e intente conservar algo de esa entidad movediza resulta también arrastrada por ésta.

\section{Conclusión}

A lo largo de este texto pudimos ver la importancia que tiene para $S$. Weil el momento de la percepción. El seguimiento que realizamos a la figura de Proteo en la primera parte nos permitió ver el alcance que tiene, para la filósofa, el presente sensorial. En efecto, es el instante presente el que nos da la vida del fenómeno, y es del encuentro con éste que logramos acceder a la inteligibilidad del espacio y del tiempo, condiciones estructurales de la realidad humana. Entendimos pues que, en última instancia, estas dos dimensiones revelan nuestra condición: buscamos inmovilizar lo movedizo, pero vivimos en lo movedizo. Es así como vimos, en la segunda sección de este escrito, que Weil subraya no solamente el carácter escurridizo e inaprehensible del tiempo, es decir que no es posible asirlo, sino también su carácter desapropiador. En efecto, en último término, no podemos ni asir ni apropiarnos nada, y más aún, perdemos, segundo a segundo, la aprehensión que manteníamos con las cosas por el intermedio de las ideas. Nuestro pensamiento y nuestro cuerpo son arrastrados por el tiempo: lo observamos correr como si fuera un río, pero somos arrastrados por éste, y no podemos salir de él para observarlo desde un punto inmóvil. Nos perdemos a nosotros mismos como en una irremediable lucha por construir un castillo de arena al borde del mar, pues apenas edificamos, ya se nos escapa, líquido, entre los dedos, lo edificado. No logramos ni aprehender el tiempo ni las cosas en su curso, porque estamos, en sus aguas vertiginosas, nosotros los que pretendemos apropiarnos todo, poseerlo todo, atarnos a todo, radicalmente desapropiados, desposeídos, desarraigados.

RUIZ JIMÉNEZ, Juan Manuel. Proteus and the expropriation of time in Simone Weil. Tans/form/ação, Marília, v. 40, n. 3, p.113-132, Jul./Set., 2017.

cuál de estos dos tiempos es más que el otro el tiempo. [...] esta diferencia, que se revela por el hecho de que el hombre «tiene» tiempo, está fundado en el deseo." (CASPER, 1985, p. 244). 


\begin{abstract}
In this work we study the genesis of Simone Weil's conception of perception. We discuss her use of the notions of time, space, and the mythological figure of Proteus, analyzing some of the author's key early texts. Our goal is to then make clear the appearance of the main important theoretical bases that organize Weil's phenomenology in her mature years. In this way, we try to demonstrate that although the perceptive process as conceived by the young Weil is strongly influenced by Kantian phenomenology, it already appears as an original contribution with regard to the relation between the consciousness of the subject and the spatiotemporal data revealed in the apprehension of the object.
\end{abstract}

Keywords: Proteus. Time. Space. Perception. Desire

\title{
REFERENCIAS
}

CASPER, B. Le temps sauvé. Cahiers Simone Weil, París, v. 8, n. 3, p. 240-252, 1985. (Simone Weil et le problème du temps).

CHENAVIER, R. Simone Weil, une philosophie du travail. Paris: Cerf, 2001.

DAVID, P. L'absolu peut-il faire l'objet d'une science expérimentale? Cahiers Simone Weil, París, v. 35, n.1, p. 29-88, marzo 2012. (Le surnature chez Simone Weil II).

DESCARTES, R. Euvres. París : Gallimard, 1953.

. Règles pour la direction de l'esprit. París: Livre de Poche, 2002.

GABELLIERI, E. Être et don: Simone Weil et la philosophie. Louvain; Paris: Éditions de 1)Institut Supérieur de Philosophie Louvain-la-Neuve ; Éditions Peeters, 2003.

JANIAUD, J. Simone Weil, l'attention et l'action. París: Presses Universitaires de France 2002.

KAHN, G. La dialéctique du temps chez Simone Weil. Cahiers Simone Weil, París, v. 8, n. 3, p. 221-239,1985. (Simone Weil et le problème du temps).

KANT, I. Critique de la raison pure. París: GF Flammarion, 2001.

MIKLOS, V. La métaphysique religieuse de Simone Weil. París: L’Harmattan, 1997.

MOLARD, J. Simone Weil Sa vie : son enseignement. Sury En Vaux: A à Z Patrimoine, 2004.

MÜLLER, W. Simone Weil et la question de l'histoire du salut. Cahiers Simone Weil, Paris, v. 24, n. 2, p. 89-102, 2001. (Le temps, le salut).

RIVIALE P. La pensée libre: essai sur les écrits politiques de Simone Weil. París: L'Harmattan, 2004.

SCHLETTE H. R. Histoire des religions et "théologie » des religions chez Simone Weil. Cahiers Simone Weil, Paris, v. 24, n. 2, p. 73-158, 2001. (Le temps, le salut).

WEIL, S. Euvres completes Tome I: premiers écrits philosophiques. Paris: Gallimard, 1988. 
RUIZ JIMÉNEZ, J. M.

. Euvres completes TOME VI: Cahiers. Paris: Gallimard, 1994.

Recebido em 24/08/2015

Aceito em 12/12/2016 